\title{
Die Einwirkung des Darmsaftes auf die Verdauungsprodukte verschiedenartigen Eiweißes aus dem Darm. \\ Von
}

E. S. London und S. K. Solowjew.

(Aus dem pathologischen Laboratorium des $\mathrm{K}$. Institutes für experimentelle Medizin zu St. Petersburg.)

(Der Redaktion zugegangen am 27. Juli 1911.)

In der vorhergehenden Mitteilung wurde festgestellt, in welchem Grade verschiedenes Nahrungseiweiß in den verschiedenen Abschnitten des Verdauungstraktus einer Spaltung unterworfen wird. Unter anderem wurde bemerkt, daß die in die Darmwand eintretenden Eiweißprodukte einen höheren Spaltungsgrad erreichen können, als wie ihn der Chymus aufweist. Der weitere Spaltungsprozeß kann im Darmlumen nur auf Rechnung des Darmsaftes gesetzt werden. Wir machten es uns daher zur Aufgabe, zu verfolgen, in welcher Weise der Darmsaft auf die Chymusprodukte, bei Ernährung mit verschiedenen Eiweißarten, einwirkt. Zur Untersuchung dienten dieselben aufgekochten Chymusfiltrate, die das Material für die vorhergehende Arbeit lieferten. Je $25 \mathrm{ccm}$ einer jeden Lösung wurden mit Soda alkalisch gemacht, mit $2 \mathrm{ccm}$ frischen spontanen Darmsaftes aus einer Thiry-Fistel vermischt. Sofort nach Zusatz von Thymol wurde eine Probe von $2 \mathrm{ccm}$ auf Amido-N-Gehalt nach Sörensen untersucht. Diese Bestimmungen wurden von Zeit zu Zeit wiederholt, und wenn der Spaltungsprozeß sich als mehr oder weniger konstant erwies, so wurde noch etwas Darmsaft hinzugefügt und zwar in Pulverform, um die Flüssigkeitsmenge nicht zu erhöhen. Dann wurde auch Thymol zugefügt. Das Hinzufügen des Darmsaftes wurde wiederholt, bis kein Ansteigen des Amido-N-Gehaltes mehr stattfand. Der Versuch galt dann für beendet. 
E. S. Lond on und S. K. Solowjew,

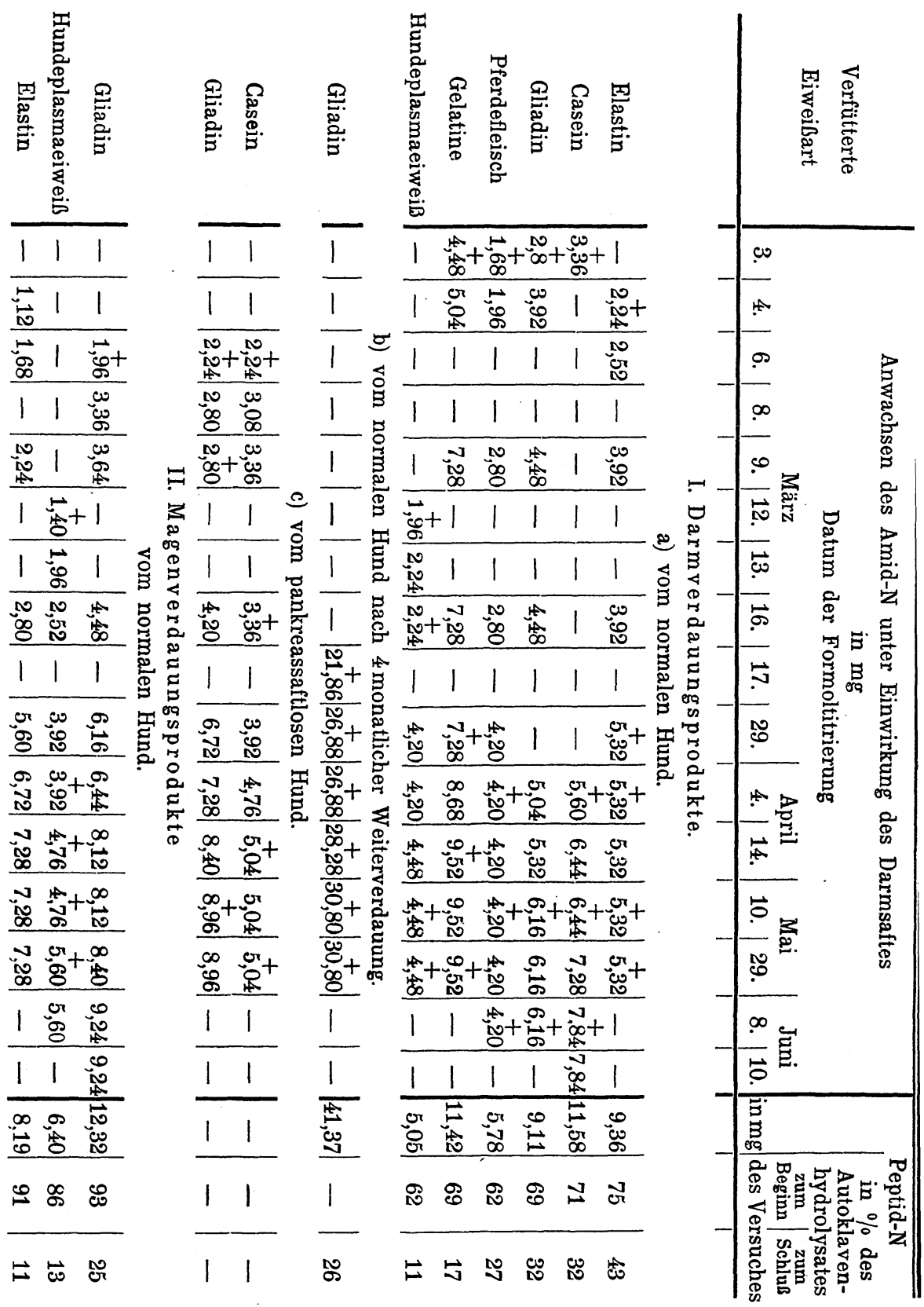


In der Lösung der Verdauungsprodukte des Caseins zeigte sich schon am nächsten Tage Gallertbildung und eine Fortsetzung der Titration konnte daher erst nach Verflüssigung der Gallerte stattfinden. In keiner von den anderen Proben fand Gallertbildung statt, doch bildete sich mit der Zeit überall ein Niederschlag. Der letztere scheint vom Darmsaft herzurühren, denn wenn man Darmsaft allein unter Thymolzusatz in den Thermostaten stellt, so bildet sich ebenfalls nach Verlauf einiger Zeit ein flockiger Niederschlag. Um eine Mißdeutung durch die Niederschläge zu vermeiden, wurde der Rest der Lösung filtriert und in 3 vollständig gleiche Teile geteilt, von denen einer auf seinen Gesamt-N-Gehalt nach Kjeldahl, einer auf seinen Amid-N-Gehalt und der dritte auf seinen Peptid$\mathrm{N}$-Gehalt untersucht wurde.

Aus den in der beiliegenden Tabelle angegebenen Zahlenwerten geht hervor, daß unter den Verhältnissen und im Rahmen unserer Versuche der Darmsaft

1. kein einziges Eiweiß zur Spaltung aller Peptidverbindungen bringt;

2. daß dem Grade der Spaltung nach die verschiedenen Eiweißarten sich im allgemeinen in derselben. Weise ordnen lassen, wie es bei der Einwirkung des Chymus der Fall ist (ansteigend): Elastin, Casein, Gliadin, Pferdefleisch, Gelatine, Hundeplasmaeiweiß. 